\title{
MOOCs as a tool to connect higher education and professional experience? Experiences from a student-made MOOC on E-Learning
}

\author{
J. Griesbaum*, M. Görtz** \\ * University of Hildesheim, Institute of Information Science and Language Technology \\ ** Accenture Strategy, Talent \& Organization
}

\begin{abstract}
This paper describes results from a student-made MOOC (Massive Open Online Course) on E-Learning. The main focus of interest lies on two aspects. Firstly, to explore the potential of using the process of creating a MOOC as a teaching method and secondly, to get insights into the affordances and outcomes linked to a cooperation with a knowledge-based company during the course of events of the MOOC. Both concepts aim for an improvement of quality in higher education by combining the concept of "learning by doing" with the initiation of communication between students and professionals in the field. On the one hand, the data shows that employing the task of building a MOOC as a teaching method is a very worthwhile didactic approach to initiate a complex and authentic learning scenario. On the other hand, the outcome indicates that the realized level of participation is expandable.
\end{abstract}

Keywords: Collaborative E-Learning, MOOC, Higher Education, Professional Experience

\section{Introduction}

The diffusion of MOOCs and the corresponding public and scientific discussion on the topic sparks the field of E-Learning in many ways and with great impact. It is therefore not surprising that MOOC research encompasses a wide span of topics. The Department for Business Innovation \& Skills (Haggard, Gore, Inkelaar, Lawton \& Katsomitros, 2013) and the Norwegian MOOC Commission sub-report (Time for MOOCs, 2013) provide an overview and a review of the literature used in this field of study. According to that, the didactic configuration of learning processes in MOOCs can be seen as an important field of research. The most prominent debate on this subject is probably on the differences of cMOOCs vs. xMOOCs. MOOCs originated as learning environments that correspond to and realize connectivist ideas of (cooperative) learning (cMOOCs). In contrast, the rising popularity and media presence of MOOCs are the result of the success and large audiences of courses offered on platforms like Edx, Udacity and Coursera that predominately follow a docent-centric knowledge distribution metaphor (xMOOCs) (Blom, Verma, Li, Skevi \& Dillenbourg, 2013). One may argue that this kind of "massification of learning" (Yuan \& Powell, 2013) comes with a price: a rather low level of didactic quality and learning scenarios which can often barely claim to address the higher levels of learning goals as described by different taxonomies, e. g. synthesis, evaluation, or metacognitive knowledge (Krathwohl, 2002). Hence, at present, learning experiences in MOOCs are often far-flung from the quality of discourse and interaction based learning processes as argued by theoretical approaches that aim beyond a knowledge acquisition metaphor, e.g. O'Donnel (2006), Scardamalia and Bereiter (1994), Slavin (1996), Siemens (2005). But the current debate on learning in MOOCs should not be restricted to a rather dichotomic discourse on "antiquated" and "up-to-date" views on learning. The concept and diffusion of MOOCs is directly connected to the idea and the adaption of socially unlimited communication. Seen from 
this point of view, MOOCs are an opportunity and playground to think of learning as an interaction of different people and groups in new ways.

This is the starting point of our work. We aim to explore the potentials of MOOCs for enhanced in-class learning and to connect stakeholder groups which were usually separated in learning. The first goal is to explore the concept of MOOCs as an in-class teaching method in which students are given the task to draft, implement, execute and evaluate a MOOC. Such a didactic setting can be seen as a complex and authentic task to initiate and foster self-initiated and autonomous learning on part of the students. The second goal is to link theory and practice by connecting students with practitioners. Students should elaborate basic concepts and theories for practitioners of the profession. In turn, practitioners should provide feedback with regard to the needs and experiences of practitioners daily work life, thus enriching the learning experiences of the students. In the following, the configuration and results of an exploratory case study are described. The paper starts with theoretical considerations about the learningrelated added values of this MOOC scenario. Then, the configuration of the MOOC and its execution are delineated. Following that, the outcomes are analyzed. The paper closes with an estimation of the added values and the limitations of this concept.

\section{Approach and Concept}

Figure 1 gives an overview of the structure of the MOOC and the stakeholders' interaction in this case study to illustrate the following argumentation.

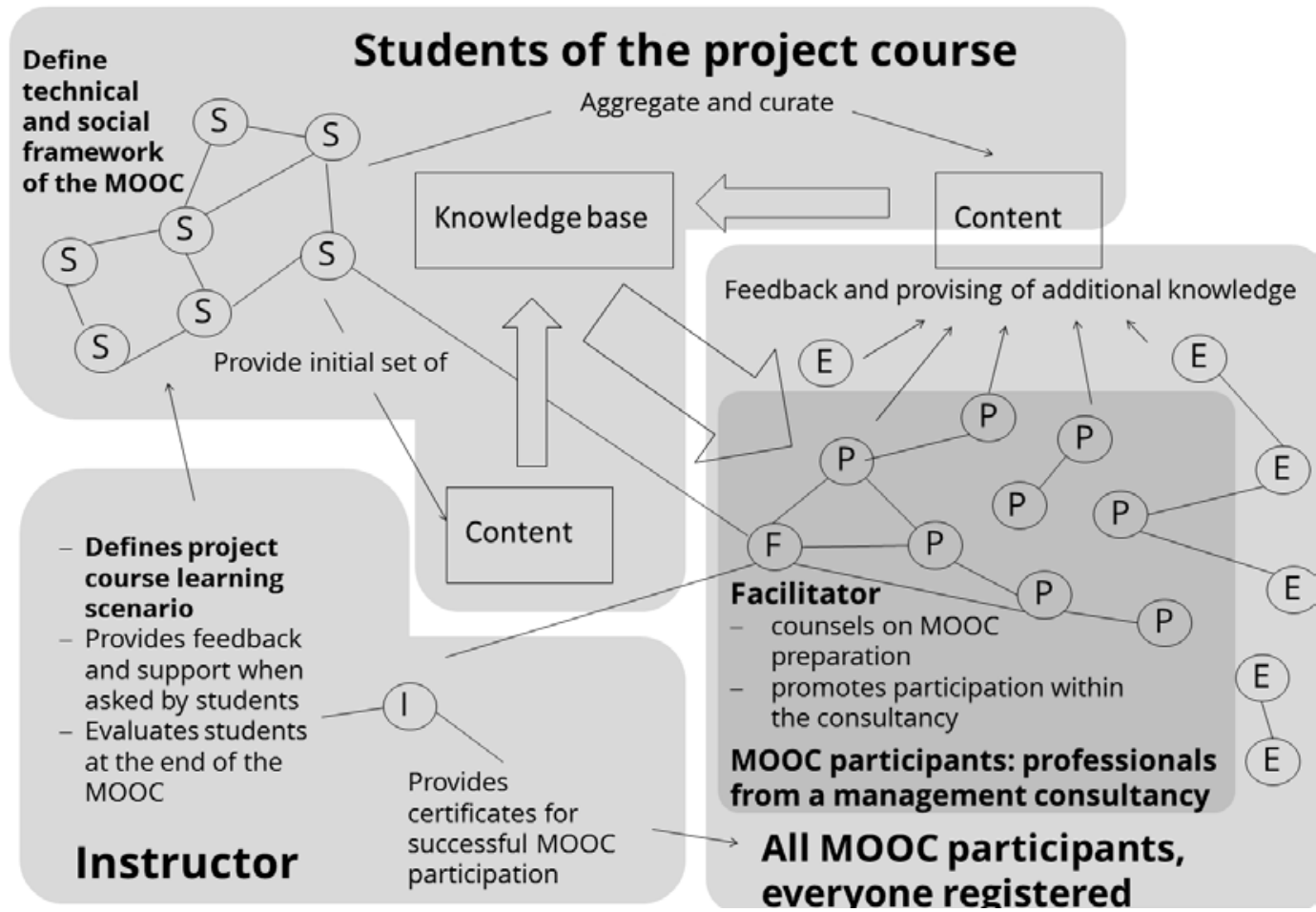

Figure 1. MOOC structure: interaction of stakeholders 


\section{Organizational context of this MOOC}

Our didactic scenario is complex. It encompasses a regular project course as an internal learning scenario at the university and a MOOC which originated as a result of students learning activities within the project course. The course in which the MOOC is developed and executed is a project course and part of the module "e-learning", in which advanced students of the master programs "International Information Management" and "Information Management and Information Technology" at the University of Hildesheim collectively acquire practical skills and knowledge. During the winter term of 2013 and 2014, the learning task of the project course was to build up and execute a MOOC on the topic "Collaborative E-Learning". The basic layout of this learning scenario was defined by the instructor of the project course, who is also the first author of this paper. To alleviate differentiation between the two courses within the didactic scenario, we refer to the project course of the students of the master programs as PC-EL and to the MOOC on the topic collaborative learning (which is developed in PC-EL) as MOOC-CL.

\section{Actor group and roles}

The following table gives an overview of stakeholders and their roles in this learning scenario as defined by the instructor at the start of the project course.

Table 1. Stakeholders and their roles in the learning scenario

\begin{tabular}{|l|l|l|}
\hline Stakeholder & PC-EL & MOOC-CL \\
\hline Students of the project course & Learners & Instructors and learners \\
\hline University instructor & Instructor & Quality manager, recipient \\
\hline $\begin{array}{l}\text { Facilitator from a management } \\
\text { consultancy }\end{array}$ & Advisor & Promoter, Learner \\
\hline $\begin{array}{l}\text { Professionals from } \\
\text { management consultancy }\end{array}$ & - & Learners \\
\hline Everyone interested & - & Learners \\
\hline
\end{tabular}

There are five stakeholder groups. Three of them are active both in the project course the PC-EL and the MOOC-CL. The role of these actor groups is different in the two courses. In the project course, students are learners. They learn about e-learning and knowledge management by developing an open learning scenario with regard to these topics, the MOOC-CL. Then, during the execution of the MOOC-CL, they act as instructors, providing the initial MOOC content. In addition, students initiate and moderate the learning process of the MOOC participants. The university instructor defines the learning scenario of the project course PC-EL. He is not actively involved in the execution of the MOOC-CL, but serves as a kind of quality manager with respect to the content provided by the students. Else, he is a passive recipient of the MOOC, 
not interfering with the course of events to maximize autonomous MOOC control on part of the project course students. The third actor is the facilitator from a management consultancy who is also the second author of this paper. Whereas the instructor defined and controlled the learning scenario of the PC-EL, the task of the facilitator was to announce and promote the MOOC-CL within the cooperating management consultancy. During the MOOC development, he additionally gave advice to students concerning learning related information needs of the professionals in the consultancy.

The last two actor groups correspond to that kind of participants which could be addressed as MOOC learners. In our scenario, the core target group were professionals in the field, that means knowledge workers professionally counseling customers with regard to knowledge related activities to foster information management and knowledge management in middle to large sized companies. Still, the MOOC-CL follows the "open paradigm" and is not restricted to a certain audience. Hence, the MOOC-CL is open for everyone interested.

\section{Conceptual considerations on learning related advantages of the learning scenario}

Why could it be worthwhile to employ the task of building up and executing a MOOC as an in-class teaching method? Why to connect higher education and professional experience in a MOOC based learning scenario? In short, such a scenario realizes a "learning by doing" approach and tries to initiate exchange between theory and practice by an ongoing dialog between students and professionals in the field.

For the students of PC-EL three core advantages can be stated: A) the learning scenario of PC-EL realizes an authentic and complex learning task. B) The MOOC-CL creates a space for discourse and feedback from the community. C) The MOOC-CL provides a room to build up online identity and reputation.

With respect to the management consultancy and its professional workforce and all learners in the MOOC-CL further advantages can be argued. D) The MOOC provides a free course to a topic which is relevant for professionals in the field. And finally, E) the MOOC offers businesses (especially the directly involved consultancy company) new options to get in direct contact with potential candidates for open positions.

\section{MOOC configuration and execution}

To give an orientation, the following figure provides an overview of the course of events of the PC-EL and the MOOC-CL. 


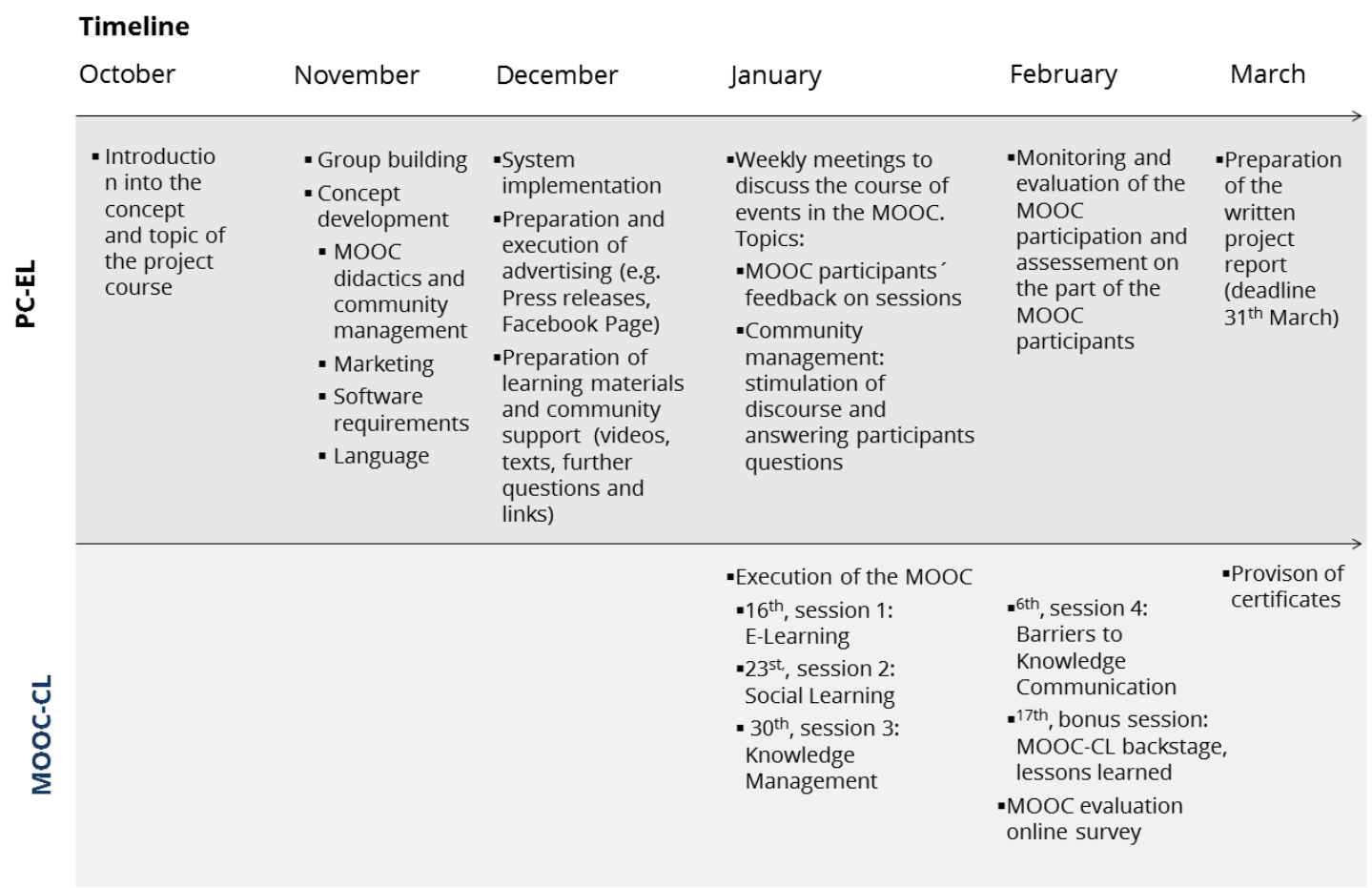

Figure 2. Course of events of PC-EL and MOOC-CL

At the start of the project course, the instructor introduced the students to the concept of the course and provided some basic suggestions concerning self-organization, group coordination, and work packages.

After that, the students took over the management of the course. The instructor restricted himself on a guide role, giving feedback only when explicitly asked for and providing infrastructural services, like preparing and handing out certificates to MOOC participants. From that date on, the students realized a truly self-controlled constructivist learning scenario. First, students determined basic aspects of selforganization and the MOOC-CL. As a starting point, it was decided to follow a connectivist paradigm in MOOC development. Hence, MOOC-CL should rather correspond to a cMOOC than a xMOOC. Group formation resulted in different groups: project management, content development, community management, controlling, software configuration and support, and marketing. Next, the content of the MOOCCL, the time schedule and the number of MOOC sessions were decided. Every session was prepared and executed by a specific session or content group.

After these basic aspects were determined, the MOOC-CL was prepared. CourseSites, a free MOOC software by Blackboard, was chosen as the software infrastructure. The choice was not without problems. On the one hand, the system provided the necessary technical features and was easy to setup and configurate. On the other hand, there were login and content submission related problems with Internet Explorer 9, the standard browser used by the participants of the management consultancy.

The marketing team decided on a broad range of advertising measures, including online as well as classic marketing channels. For content development a storytelling concept was worked out, telling the story of a student who faces different learning and 
knowledge management related problems as a recurrent theme throughout all four MOOC sessions. Videos (with a length of a few minutes) and photo stories were prepared as the primary format for knowledge transfer. External experts were also included in the videos. For visualization, the software tools Videoscribe, PowToon, and ComicLife 3 were employed. All videos produced for the MOOC can be found at https://www.youtube.com/channel/UCH0mIduX62yZTNUWKhe0svw.

In addition, to initiate and support knowledge development within the MOOC community, a specific community management concept was developed. Firstly, discussions for each session were prepared and initiated. During the sequence of the four sessions, a successively larger variety of communication and knowledge generation tools was provided. For each of the tools an initial inventory of content was prepared. Finally, students prepared questionnaires for an evaluation and to give the participants an opportunity to post requests for following sessions.

\section{Results and Discussion}

The analysis is structured with regard to the different stakeholder groups in the two courses forming the whole learning scenario. First, learning processes and outcome for students in PC-EL are evaluated. Following that, MOOC-CL related values for the learners in the MOOC are discussed. Finally, both perspectives are brought together.

\section{Learning success of students in PC-EL}

The analysis of students' learning success is based on the assessment of the participants' learning processes and outcome on part of the instructor and on the students' selfestimation captured by a survey at the end of PC-EL. According to the estimation of the instructor, the course of events as described in section 3 strongly indicates that the learning scenario successfully evoked a widely self-directed and self-controlled learning process on part of the students. In PC-EL, students were very active and highly involved. After the introduction in the course, which was given by the instructor, the students organized in-class and virtual learning activities autonomously. During the active phase of the MOOC-CL sessions, the students often decided to have additional face-to-face project course meetings.

As the preparation and execution of the MOOC-CL was well-founded and clearly presented in the final in-class presentation and elaborately described and argued in the project report, the group work was rated with the best grade, which can be seen as a direct measurement of learning success. This corresponds with the students' selfevaluation of their learning success. All 14 students took part in the final course evaluation. Table 2 shows the results. 
Table 2. Results of the final course evaluation in PC-EL

\begin{tabular}{|l|c|}
\hline Question & Mean Value (SD) \\
\hline q.1) Workload & $1.64(0.48)$ \\
\hline $\begin{array}{l}\text { q.2) Learning success with regard to the content related aspects of the } \\
\text { course }\end{array}$ & $1.36(0.72)$ \\
\hline q.3) Learning success with regard to the project management & $1.71(0.59)$ \\
\hline q.4) Charateristics of team work & $1.21(0.94)$ \\
\hline q.5) Motivational effect of team work & $0.86(0.83)$ \\
\hline
\end{tabular}

$\mathrm{N}=14$, measured on a 5-stage scale ranging from -2 (q.1, q.2, q.3 and q.5="very low", q.4="cooperative") to +2 (q.1, q.2, q.3 and q.5="very high", q.4="collaborative")

Learning success was assessed as high with a mean value higher than 1 (q.2 and q.3). Workload (q.1) was also assessed as high, indicating that students were highly involved. Motivation can also be interpreted as positive (q.5). The characteristics of group work can be estimated as very positive because the group process was judged as rather collaborative (q.4). Seen from socio-genetic and socio-cultural perspectives of learning, real collaboration has to be seen as a prerequisite for the occurrence of processes like cognitive conflicts, externalization of knowledge, and consensus building. Such processes in turn are causative for enhanced learning success in group learning. In sum, with a positive motivation, strong immersion and high learning success, students assessed their learning success very positively. Overall, both from the instructor's perspective and students' view on their learning, results with regard to learning success are very encouraging.

\section{MOOC-CL values}

To determine the value of the MOOC-CL, audience reach, participation and MOOC participant evaluation are analyzed.

\section{Audience reach}

Audience reach is captured with data provided by CourseSites which is further refined and aggregated. All data provided encompasses user actions between January 16th and February 28th. Overall, till the end of February, 277 participants registered on MOOCCL. Audience reach is operationalized as the number of unique users per MOOC session.

MOOC-CL started with 200 users in session 1. Thus, the MOOC can be assessed as rather small with regard to the number of participants. Nevertheless, a number of 200 users is not insignificant. It shows that the MOOC still reached an audience size corresponding to a multitude of standard courses. In the following sessions the number of users declined. This is a pattern typical for MOOCs (Koller, 2012). The different 
elements of the four sessions were used to a different degree. On the due date of 12th of February (one week after the fourth session) the number of total requests in forums $(n=17,657)$ more than doubles the amount of request of provided learning materials $(n=8,115)$. This indicates that discourse and collaborative knowledge production formed a central part of the learning experience of all MOOC participants.

\section{Knowledge generation and participation}

Resources prepared by the students of PC-EL formed the core and bulk of the knowledge which was created in MOOC-CL. Students prepared 11 videos, 5 photo stories, 9 forums, 6 blogs and 9 wikis. Collaborative knowledge generation primarily focused on the discussions in the forums. 308 forum posts were written, roughly half of them by the students of PC-EL (147 posts) and half of them by the MOOC-CL participants (161 posts). Thus, knowledge generation in forums can be assessed as successful. In contrast to that, participative knowledge generation in other tools (blogs, wikis) was rather sparse.

\section{Estimation of the participants of MOOC-CL}

At the end of session 4, a final questionnaire was prepared for the MOOC-CL participants to enable them to provide feedback with respect to the quality of the MOOC. 19 participants took part in the survey. 95\% rated the quality of the MOOC as high or very high. With regard to learning, nearly $50 \%$ of the participants rated the videos as the primary means for knowledge acquisition. $85 \%$ of the participants assessed the forums as their preferred tool for interaction. Furthermore, users provided feedback with regard to their motivation for MOOC-CL participation and the learnings achieved. Data denotes two different motivations for MOOC participation. First, a MOOC format specific perspective. Participants took part because they were interested in MOOCs as a new "tool" for learning. The second motivation is content related. Participants took also part in MOOC-CL because they were interested in the topic of the MOOC “collaborative learning”. According to the survey data, learnings achieved with respect to learning format related goals focused on aspects of MOOC organization and tools for video production. Feedback on content related learning goals indicates a consolidation of already available knowledge which was deepened in the forum discourse.

In sum, this chapter indicates manifold values of MOOC-CL for the professionals of the management consultant agency and the open web public. The number of participants shows a certain amount of interest and demand on the MOOC-CL. In addition, real discourse and collaborative knowledge generation can be observed. Finally, learning and learning outcomes are assessed as positive and of high knowledge value. On the one hand, these results sound encouraging. On the other hand, they need to be put in perspective. As a whole, audience reach is of a rather low level and therefore, the knowledge related values for the professionals of the management consultant agency and the open web public remain of limited magnitude. 


\section{Success of connecting higher education with professional experience}

Finally, was the learning scenario able to invoke a connection between higher education and professional experience?

In sum, we can conclude that the cooperation was basically successful. At the same time, we see that success of this cooperation strongly relates to the amount of participation of the management consultancy professionals. Regarding to this, the success rate was rather basic as only $10 \%$ of the target group took part in MOOC-CL. Two kinds of hurdles for participation were identified, organizational and technical factors. Both pointing to requirements which should be considered in further experiments. Firstly and probably most important, the effort taken in participating a MOOCshould be accounted for in the work schedule. Secondly, the compatibility between the MOOC software and the technical infrastructure of the company needs to be assured beforehand.

\section{Conclusions}

As an overall estimation, the conclusion here is that employing a MOOC as an in-class teaching method in the sense of a "students teaches the web community" approach can be seen as worthwhile. However, it is a teaching method, which deserves further exploration. The case study shows the limits of this concept but also indicates positive learning effects on part of the students and manifold values for the web community. At the same, it turns out that a stronger and explicit connection to professional experience is not achievable that easily. At least, the configuration tested in this case study shows room for improvement.

\section{References}

Blom, J., Verma, H., Li, N., Skevi, A. \& Dillenbourg, P. (2013). MOOCs are More Social than You Believe. eLearning Papers, 33. Retrieved from https://oerknowledgecloud.org/sites/oerknowledgecloud.org/files/Fromfield_33_1.pdf

Cress, U. \& Kloos, D. C. (2014). Proceedings EMOOCs 2014, the Second MOOC European Stakeholders Summit, Feb. 10-12, Lausanne (Switzerland).

Fournier, H., Kop, R. \& Durand, G. (2014). Challenges to Research in MOOCs. MERLOT Journal of Online Learning and Teaching, 10(1), Retrieved from http://jolt.merlot.org/vol10no1/fournier_0314.pdf

Griesbaum, J. (2014). Students as teachers in MOOCs: The double gain of MOOCs as an in-class teaching method experiences from a student-made MOOC" Online Data Privacy. International Journal of Information and Education Technology, 4(1), 2934.

Haggard, S., Gore, T., Inkelaar, T., Lawton, W. \& Katsomitros, A. (2013). The Maturing of the MOOC. Literature review of Massive Open Online Courses and 
other forms of Online Distance Learning (BIS Research Paper Number 130). London: Department for Business Innovation \& Skills. Retrieved from https://www.gov.uk/government/uploads/system/uploads/attachment_data/file/24 0193/13-1173-maturing-of-the-mooc.pdf.

Ingham, A. G., Levinger, G., Graves, J. \& Peckham, V. (1974). The Ringelmann effect: Studies of group size and group performance. Journal of Experimental Social Psychology, 10(4), 371-384.

Johnson, D.W., Johnson, R.T. \& Holubec, E.J. (1998). Cooperation in the classroom. Edina: Interaction Book.

Koller, D. (2012). MOOCs on the move: How coursera is disrupting the traditional classroom [Podcast]. In Knowledge Wharton (2012), Retrieved Sep. 9, 2014 from http://knowledge.wharton.upenn.edu/article/moocs-on-the-move-how-courserais-disrupting-the-traditional-classroom/

Kop, R. \& Hill, A. (2008). Connectivism: Learning theory of the future or vestige of the past? The International Review of Research in Open and Distance Learning. 9(3). Retrieved from http://www.irrodl.org/index.php/irrodl/article/view/523/1103

Krathwohl, D.R. (2002), A Revision of Bloom's Taxonomy: An Overview. Theory into Practice, 41, pp. 212-218.

N.A. (2013), Time for MOOCs, Norwegian MOOC Commission sub-report. Retrieved May 5, 2014 http://www.regjeringen.no/upload/KD/Time_for_MOOCs.pdf

O'Donnel, A. M. (2006). The role of peers and group learning. In Alexander, P. A. \& Winnie, P. H. (Eds.), Handbook of educational psychology (pp. 781-802). $2^{\text {nd }}$ ed. Lawrence Erlbaum Associates.

Scardamalia, M. \& Bereiter, C. (1994). Computer support for knowledge building communities. Journal of the Learning Sciences, 3, 265-283.

Siemens, G. (2005). Connectivism: A Learning Theory for the Digital Age. International Journal of Instructional Technology and Distance Learning. Retrieved from http://www.itdl.org/journal/jan_05/article01.htm

Slavin, R.E. (1996). Research for the future. Research on Cooperative Learning and Achievement: What We Know, What We Need to Know. Contemporay Educational Psychology, 21, 43-69.

Yuan, L. \& Powell, S. (2013). MOOCs and disruptive innovation: Implications for higher education. eLearning Papers, 33. Retrieved from http://www.openeducationeuropa.eu/en/download/file/fid/27007 